\title{
RECENT PROGRESS AT IMFM ON EXCIMER LASERS AND THEIR APPLICATIONS
}

\author{
B. FONTAINE, Ph. DELAPORTE, B. FORESTIER, M:SENTIS, M. AUTRIC, \\ Ph. BOURNOT, D. DUFRESNE and G. INGLESAKIS \\ IMFM-UM34 CNRS, Aix-Marseille University, 1 rue Honnorat, F-13003 Marseille, France
}

\begin{abstract}
Recent progress made at IMFM on excimer lasers and their applications is presented. It mainly concerns high power and pulse rate frequency discharge excimer lasers, high energy E-Beam pumped excimer lasers, new excitation schemes, photolysis excitation of uv-visible lasers by sliding discharges, new vuv sources using ionic excimers and processing or elaboration of materials with excimer lasers.
\end{abstract}

\section{1.- Introduction}

Numerous potential applications, in particular in the fields of material processing and photochemistry and more generally in energy transfer, have recently stimulated considerable interest in the scaling of excimer lasers to higher output energy, pulse length, pulse repetition frequency, average laser power and efficiency. Moreover there is presently a need in shorter wavelength (vacuum ultraviolet) high power pulsed laser sources. In parallel, progress on excimer laser sources has induced studies on specific applications of these sources $(t)$.

IMFM has been strongly involved since twenty years in studies of high power pulsed lasers and their applications. Current researches of New Lasers and Laser Matter Interactions Groups on excimer lasers and related studies concern: a) high power and pulse rate frequency discharge excimer lasers, b) high energy E-Beam pumped excimer lasers, c) new excitation schemes to increase efficiency and pulse length of these sources, d) photolysis excitation of uv-visible lasers by sliding discharges, e) new vuv sources using ionic excimers (isoelectronics with classical excimers), f) processing and elaboration of materials with excimer lasers.

\section{2.- High power and pulse rate frequency discharge excimer lasers}

A program to investigate the key parameters which may limit scaling of the $\mathrm{XeCl}$ excimer laser $(\lambda=308 \mathrm{~nm})$ to very high average power $\left(\mathrm{P}_{1} \approx 1 \mathrm{~kW}\right)$ has been undertaken. This program is developped in the frame of EUREKA EU 205 program (Eurolaser-excimer lasers), with the aim to optimize such a laser in terms of energy per shot, efficiency and pulse rate frequency. Experiments are is made on the advanced test-bed LUX (Laser Ultraviolet préionisé par rayons $X$ ) developped at IMFM, for conditions of very high average power $\left(\bar{P}_{1} \approx 100-1000 \mathrm{~W}\right)$ and repetition rate $(>1 \mathrm{khz})$. The study includes theoretical, numerical and experimental investigations on possible advanced excitation schemes in order to increase laser pulse length and system efficiency (C-L.C, Double discharge, phototriggering). Behavior and damping of induced waves and couplings beetwen discharge, flow and laser beam at very high PRF are also actively studied. Important advance has been obtained on reduction of laser pulse to pulse fluctuation and energy per shot decrease at high PRF by waves damping and inductive discharge stabilisation $(2-4)$. It as also been possible to run a photoswitched XeCl laser up to $400 \mathrm{~Hz}$ (power supply limited (5). Fig. 1 shows pulse to pulse energy change measured on LUX test bed with 2 rd generation laser head including a porous segmented electrode. 


\section{shot 1}

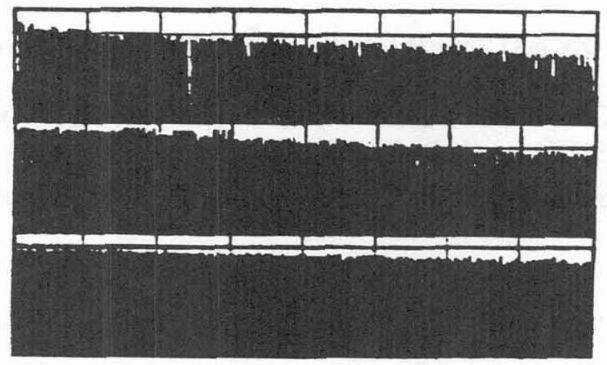

$1660 \mathrm{~Hz}$

$1000 \mathrm{~Hz}$

\section{$500 \mathrm{~Hz}$}

Fig. 1 Pulse to pulse laser energy change on LUX v.s. P.R.F.

\section{3 - High energy E-Beam pumped excimer lasers}

A high energy E-Beam pumped KrF laser called KIR for KrYpton Intense Radiation has been designed and çonstructed for high energy pulsed uv laser applications. The laser cell with a volume of $100 * 22 * 22 \mathrm{~cm}^{3}$ and $21 * 21 \mathrm{~cm}^{2}$, is excited by two electron guns (600 kV, $50 \mathrm{kA}, 500 \mathrm{~ns}$ ) (double sided pumping scheme). Numerical simulations of the electron energy deposition (Monte-Carlo method) 6 ) and the laser kinetics $(7)$ have allowed to optimize this system in term of efficiency. A detailled experimental study of energy deposit in the laser cell has shown an uniform distribution of E-Beam current of about 10-12 A/cm2. This oscillator delivers routinely $160 \mathrm{~J}$ in $400 \mathrm{~ns}(5,1 \mathrm{~J} / \mathrm{l})$ at $\lambda=248 \mathrm{~nm}$ using a confocal unstable resonator. Very recent improvements in cathod design allows to obtain over $200 \mathrm{~J}$ of laser energy per shot from this laser. Fig. 2 shows typical diode voltage, diode current, diode pumping power and laser pulse time variations, while, in Table 1 are presented characteristics of KIR.



Diode Voltage

$V_{\mathrm{HV}}=100 \mathrm{kV} / \mathrm{div}$

TimeBase: 200 ne/div

Diode Courant

IC $=11.75 \mathrm{kA} d i v$

TimeBasa: 200 ns/div

Diode Pumping Power

$P_{W}=510^{\circ} \mathrm{W}$

TimeBase: 200 ns/div
Fig. 2 Typical electrical and optical waveforms from KIR KrF laser

\footnotetext{
Laser Pulse

(Arbit. Unit)

TimeBase: 200 nsidly

Measured laser energy

$E_{J}=142$ Joulas
} 


\begin{tabular}{|ll|ll|}
\hline OUTPUT ENERGY & $160 \mathrm{~J}$ & OUTPUT INTENSITY & $\mathrm{I}_{\mathrm{d}}=1.2 \mathrm{~mW} / \mathrm{cm}^{2}$ \\
PULSE DURATION & $400 \mathrm{~ns}$ & INTRINSIC EFFICIENCY & $4 \%$ \\
OUTPUT FLUENCE & $0.6 \mathrm{sm}^{2}$ & OVERAL EFFICIENCY & $0.3 \%$ \\
\hline
\end{tabular}

T. 1 Kir excimer laser Characteristics $(\lambda=248 \mathrm{~nm})$

\section{4.- New excitation schemes for efficiency and pulse length increase}

An experimental and numerical study of a small volume long pulse $X$-ray preionized $\mathrm{XeCl}$ laser using a double discharge with a fast ferrite magnetic switch has allowed high efficiency $X$-ray preionized discharge $\mathrm{XeCl}$ laser excitation with $\mathrm{Ne} / \mathrm{Xe} / \mathrm{HCl}$ mixture in $50 \mathrm{~cm} 3$ active volume $(25 * 2 * 1$ $\mathrm{cm} 3$ ) at relatively low pressure (2,5 atm.). A 3,2 \% efficiency in energy and $4 \%$ in power at maximum with up to $140 \mathrm{~mJ}$ extracted optical energy, in a $150 \mathrm{~ns}$ (FWHM) laser pulse, has been measured, for single shot, with this not optimized device $(8)$. A complete model of long pulse $\mathrm{XeCl}$ laser excited by double discharge with ferrite magnetic switch has been made for $\mathrm{Ne} / \mathrm{Xe} / \mathrm{HCl}$ active medium ${ }^{(9)}$.

\section{5.- Photolysis excitation of uv-visible lasers by sliding discharges}

Recent works $(10)(11)$ have shown interrest of photolytic sources for laser medium excitation.

An experimental and numerical study of possibility to use the high efficiency uv-vuv emisssion from a sliding discharge on formed ferrites has started in 1990. The objectives are to understand the physics of the excitation process, to characterize the emitted energy spectral distibution and to evaluate the possibilities of this excitation scheme for laser pumping and soft X-Ray production.

\section{6.- New vuv sources using ionic excimers}

It as been observed that the recently discovered rare gas-alcali and alcali-halogene ionic excimers, which are isolelectronics to classical neutral excimers are very strong emitters in the VUV spectral range $(12-15)$.

Theoretical, numerical and experimental study of possibility to obtain strong fluorescence and laser emissions in the vuv-euv by use of rare gas-alkali ionic excimers is presently in progress at IMFM. A mixture of rare gas and alkali at high temperature and high pressure is excited by a pulsed E-Beam. Strong fluorescence emissions from $\mathrm{Xe}^{+} \mathrm{Rh}(164 \mathrm{~nm})$ and $\mathrm{Kr}^{+} \mathrm{Rb}(134 \mathrm{~nm})$ (first observation with $\mathrm{E}$ Beam pumping) have been observed $(16)$. Table 2 represents ionic and neutral excimers isoelectronicity as well as present pumping methods.

\begin{tabular}{|c|c|c|c|}
\hline Ionic excimer & Neutral excimer & Final state & Pumping process \\
\hline $\begin{array}{l}\text { Alkali - Rare gas } \\
\mathbf{R g}+\mathbf{A}-\mathbf{K r}+\mathbf{R b}\end{array}$ & $\begin{array}{c}\text { Rare gas - Rare gas } \\
\qquad \mathbf{R g}_{2}^{*}-\mathbf{K} \mathbf{r}_{\mathbf{2}}^{*} \\
\end{array}$ & $\begin{array}{l}\mathbf{R g A}+ \\
\mathbf{K r R b +}\end{array}$ & $\begin{array}{c}\text { Laser produced plasma } \\
\text { Ion beam } \\
\text { Electron beam }\end{array}$ \\
\hline $\begin{array}{c}\text { Alkali - Halide } \\
\mathrm{A}^{2+} \mathrm{X}--\mathrm{Cs}^{2+} \mathrm{Cl}-\end{array}$ & $\begin{array}{l}\text { Rare gas - Halide } \\
\mathbf{R g}+\mathrm{X}-\mathrm{XeCl}^{*}\end{array}$ & $\begin{array}{l}\mathrm{A}+\mathrm{X} \\
\mathrm{Cs}+\mathrm{Cl}\end{array}$ & $\begin{array}{c}\text { Laser produced plasma } \\
\text { Ion beam }\end{array}$ \\
\hline $\begin{array}{c}\text { Diatomic Rare gas } \\
\mathrm{Rg}_{2}{ }^{2+}-\mathrm{Ne}_{2}{ }^{2+} \\
\end{array}$ & $\begin{array}{c}\text { Halide - Halide } \\
\mathrm{X}+\mathrm{X}-\mathrm{F}_{\mathbf{Z}^{*}}\end{array}$ & $\begin{array}{l}\mathbf{R g}^{+}+\mathbf{R g}^{+} \\
\mathrm{Ne}^{+}+\mathrm{Ne}^{+} \\
\end{array}$ & $\begin{array}{c}\text { Laser produced plasma } \\
\text { Ion beam } \\
\text { Electron beam }\end{array}$ \\
\hline $\begin{array}{l}\text { Rare gas - Halide } \\
\mathrm{Rg}^{2+} \mathrm{X}-\mathrm{Xe}^{2+l}\end{array}$ & $\begin{array}{c}\text { Halide - Halide } \\
\qquad \mathrm{X}+\mathrm{X}-\mathbf{1}_{\mathbf{2}}^{*}\end{array}$ & $\begin{array}{l}\mathbf{R g}^{+}+\mathbf{X} \\
\mathbf{X e}^{+}+\mathbf{I}\end{array}$ & no observation \\
\hline
\end{tabular}

T.2 lonic and neutral excimers isoelectronicity 
7.- processing and elaboration of materials with excimer lasers

Applications using high average power, high PRF or high energy excimer lasers specificities are developped at IMFM. the sources are either LUX or KIR and also industrial lasers from SOPRA.

In situ growth of high temperature superconductors thin films using $\mathrm{XeCl}$ excimer without postannealing is studied with LUX, in collaboration with specialists of condensed matter physics. Focus is made on effects of PRF, pulse length and wavelengh on superconductor characteristics and on hydrodynamics of the plasma. High quality superconductor films with transition at $\mathrm{Tc}=90 \mathrm{~K}$ and interresting results concerning ablation and deposit processes have been obtained very recently $(17)$.

Surface processing and cleaning of metals by $\mathrm{XeCl}$ and $\mathrm{KrF}$ laser radiations is studied in collaboration with metallurgists. Effect of PRF at $\lambda=308 \mathrm{~nm}$ is investigated with LUX.

Cleaning of various materials whith low PRF industrial excimer lasers is investigated in collaboration with industrial partnairs .

Medical applications of excimer lasers, in particular photoablation of calcite atheroma in periferials are studied in vitro with $\mathrm{XeCl}$ and $\mathrm{KrF}$ lasers $(18)$.

\section{8.- Conclusion}

At IMFM-UM34 CNRS, New Lasers and Laser-Matter Interaction Groups are strongly involved in researchs on excimer lasers and their applications, with the support of DRET, EUREKA, CNRS, MRT, PACA and industriel partners. Focus is made on very high average power and PRF and high energy single shot lasers and also on specific applications of these photon sources. Advances have been recently achieved in these fields at IMFM. These researches will be developped in the future.

\section{9.- Acknowledgments}

These researchs were supported in part by french Ministry of Research, french DRET and Région Provence Alpes Cote d'Azur (PACA).

\section{References}

1. See, for example, papers on Excimer Lasers and Applications in Technical Digests, Conference on Lasers and Electrooptics (Optical Society of America, Washington, DC, 1985-91).

2. M.L. Sentis, Ph. Delaporte, B.M. Forestier and B.L. Fontaine, J. Appl. Phys. 66, 1925 (1989).

3. M. Sentis, Ph. Delaporte, B. Forestier and B. Fontaine, IEEE J. Quant. Electr., to be publ. (1991).

4. Ph. Delaporte, B. Fontaine, B. Forestier, M. Sentis, 8th GCL, Madrid, Sept. 1990, SPIE, 1397, 485 (1990).

5. M.L. Sentis, B.M: Forestier, J.P. Truong, B. Lacour, H. Brunet, Technical Digests, Conference on Lasers and Electrooptics (CLEO 91) (OSA), Baltimore, May 1991, paper CThE4, 376 (1991).

6. M.A. Aminou, Thesis, Aix-Marseille III University (1988).

7. A. Fornier, Thesis, Aix-Marseille III University (1990).

8. J.M. Hueber, B. Fontaine, B. Forestier, Ph. Delaporte, M. Sentis, Opt. Comm., to be publ. (1991).

9. M.N. Kobhio, B. L. FONTAINE, J.M. Hueber, Ph. Delaporte, B.M. Forestier, and M.L. Sentis, E.C.O.4, The Hague, Mars 1991, SPIE, 1503, (1991); also Proc. M2P, J. Physique C (1991).

10. V.S. Zuev, G.N. Kashnikov, V.V. Kirilenko, S.B. Mamaev, V.A. Sorokin, V.F. Shukorukov, So. J. Quant. Electr., 19, 748, (1989)

11. R.W.F. Gross, L.E. Schneider, S.T. Amimoto, Appl. Phys. Lett. 53, 2365 (1988)

12. J. Fiedler, L. Frey, F. Steigerwald, H. Langhoff, T. Griegel, K. Petkau, W. Hammer, Z. Phys. D, 11, 141 (1989)

13. P.S. Milar, G. Warwar, P.J. Wisoff, R. Sauerbrey, Appl. Phys. Lett. $\underline{55}, 2176$ (1989)

14. Da Xing, K.I. Ueda, H. Takuma, Japan. J. Appl. Phys. L, 30, L365 (1991)

15. T.T. Yang, V.T. Gylys, D.G. Harris, J. Opt. Soc. Am. B, $\underline{6}, 1536$ (1989)

16. Ph. Delaporte, Th. Chauvet, B.L. Fontaine, B.M. Forestier, Technical Digests, Quantum Electronics Laser Science Conf. (QELS 91 (OSA), Baltimore May 1991, paper CThE4, 376 (1991)

17. W. Marine, M. Gerry, J.M. Scotto d'Aniello, M. Sentis, Ph. Delaporte, B. Forestier , B. Fontaine, Appl. Surf. Sci., to be published (1991)

18. Ph. Piquet, Ph. Bournot, Ph. Caminat, J.F. Pellissier, C. Mercier, Lasers.in Medical Science, to be Publ. (1991) 